\title{
Knowledge, Demand and Habits Towards Novel Coronavirus Disease (COVID-19) of College Students: Cross-Sectional Survey Study of Southwest China
}

\author{
Luo $\operatorname{Lin}^{1,2 *}$, Song Naiqing ${ }^{2}$ \\ ${ }^{1}$ School of Physical Education, Guizhou Normal University, Guiyang, Guizhou Province, China \\ ${ }^{2}$ Basic Education Research Center of Southwest University, Chongqing, China \\ ${ }^{*}$ Corresponding author. Email: 5925860@qq.com
}

\begin{abstract}
Purpose: To determine the knowledge, information acquisition channels, and information topics of college students during the COVID-19 epidemic, and to provide decision makers with empirical data to help formulate future health strategies and health education strategies. Methods: Using online surveys, a total of 3059 people were surveyed among college students in three provinces in southwestern China. SPSS was used for data analysis. Results: $56.16 \%$ of college students'COVID-19 knowledge scores were good or above. During the epidemic, college students obtained the most information about COVID-19 through TV (86.6\%) and the Internet (79.4\%), and more than $80 \%$ of students were susceptible to COVID-19. All kinds of related knowledge are hoped to be further understood. Gender, grade, major, current residence, information needs, information acquisition channels, and information attention preferences will all affect the level of COVID-19 knowledge of college students. Conclusion: It is recommended that a variety of channels should be adopted more accurately, in accordance with the behavior and demand characteristics of different populations, and a variety of publicity methods should be used to timely and efficiently transmit disease-related information to the public, and guide the public to respond more actively to disease prevention and control. Combination of prevention and control methods, and detailed disease prevention and control content.
\end{abstract}

Keywords: Knowledge, Demand ,Habits, College Students, COVID-19

\section{INTRODUCTION}

On December 29, 2019, a new type of coronavirus pneumonia (COVID-19) ${ }^{[1]}$ caused by the "SARS-CoV2 " coronavirus was first discovered in Wuhan, China. Subsequently, the disease spread rapidly throughout the country. The government responded immediately and launched an unprecedented national emergency plan, including closing unnecessary businesses, public transportation, schools, and universities, publishing some preventive manuals, and providing health education to people through national and local TV programs and social media. Past research evidence of severe acute respiratory syndrome (SARS), Middle East respiratory syndrome (MERS) and Ebola shows that the public's disease-related knowledge plays a decisive role in controlling the epidemic of the disease ${ }^{[2-4]}$. In the early stage of COVID-19, we conducted a nationwide survey (January 30, 2020). The results of the study showed that only $5.4 \%$ of the public's COVID-19 knowledge score was classified as good or above. At the same time, we have also observed significant differences in the knowledge levels of different groups of people ${ }^{[5]}$. Therefore, the government not only needs to pay attention to the public's knowledge level of COVID-19, but also needs to understand the differences in behavior between different groups of people, which will help formulate response strategies. Based on this, we selected three provinces with different COVID-19 risk levels from the southwest region and conducted an online survey of undergraduate students living in these three provinces. We hope to obtain these data of college students: COVID-19 knowledge, information acquisition methods, information attention content, information needs, information acquisition habits. We will study the following issues:

How do college students know about COVID-19?

What information channels do college students use to obtain COVID-19 information every day? 
What COVID-19 information topics do college students pay attention to every day?

What information do college students want to learn about COVID-19?

Before the COVID-19 epidemic, what channels did college students usually use to obtain health information?

Will the COVID-19 risk level of the environment affect the COVID-19 knowledge and information behavior of college students?

What is the difference between college students' COVID-19 knowledge, information acquisition methods, information concerns, information demand scores, and information acquisition habits?

Will demographic factors, information acquisition methods, information attention content, information needs and information acquisition habits affect college students' knowledge of COVID-19?

\section{METHODS}

\subsection{Sample}

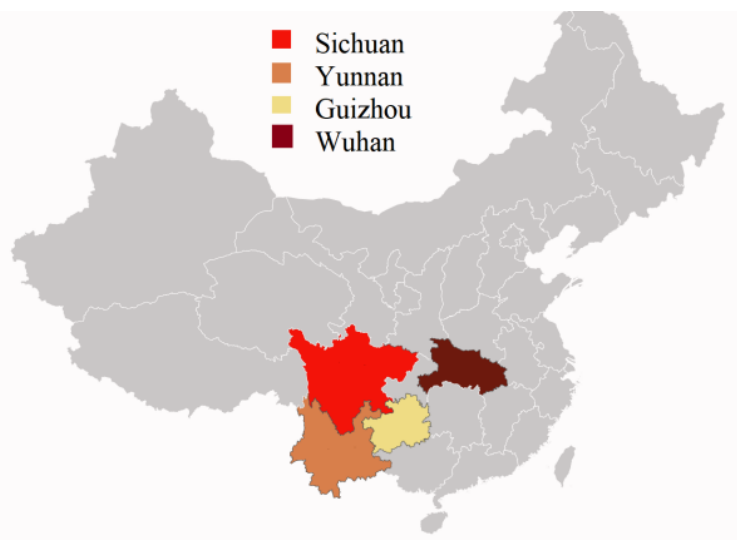

Figure 1. Geographical distribution of the study sample $(n=3059)$

This cross-sectional demographic study was conducted from March 3 to 4, 2020, using an online survey for data collection. This study selected three provinces in southwest China: Chongqing, Yunnan, and Guizhou. Their epidemic risk levels (according to the risk classification method of the China Health Commission) are high-risk, medium-risk, and low-risk. Their geographic location and their relationship with Wuhan are shown in Figure 1. This research plan surveys 1,000 college students in each province. Before the survey, online training was conducted for data collectors from these three provinces. In each province under investigation, there are 4 local data investigators who can find volunteers to assist in completing this questionnaire.The survey requires the consent of all participants. After accepting to participate in this study, the respondents conducted an electronic questionnaire survey through “Tencent QQ" or “WeChat” APP. The online survey was conducted for 48 hours, and the number of survey questionnaires was viewed 27810 times. A total of 3278 questionnaires were received. Invalid questionnaires were excluded. A total of 3,059 valid questionnaires were collected. The effective rate of questionnaires was $93.31 \%$. (Figure 1)

\subsection{Variables}

The knowledge part is based on the "New Coronavirus Infectious Pneumonia Diagnosis and Treatment Plan (6th Edition)" issued by the National Health Commission, and 13 questions have been formulated. Each question has 4 options, only one is completely correct. The correct answer is 1 point, the wrong answer is 0 points, and the full score is 13 points. A score higher than $\mathrm{P}_{75}$ is defined as good. There are a total of 9 questions in the information needs part, which are scored using the 5-point Likert scale, with a maximum score of 45 points. There are a total of 12 questions in the information acquisition habit, which are scored using the 5-point Likert scale. The maximum score is 60 points. There are a total of 7 questions in the information acquisition methods. The answer is "yes/no". The answer is "yes" and 1 point is counted. The highest score is 7 points. There are a total of 5 questions in the content of information topics, and the answer is "yes/no". The answer is "yes" and 1 point is counted, and the maximum is 5 points. The questionnaire of this study has been conducted three online discussions with experts in medicine, epidemiology and preventive medicine before being used. The reliability and validity of the questionnaire are obtained through prediction. Cronbach's Alpha: Knowledge is 0.678 , information needs are 0.956, information acquisition methods are 0.762 , information topics are 0.623 , information acquisition habits are 0.880 , and the entire questionnaire is 0.791 . Quality assurance is achieved by monitoring the data collection process, data extraction, software data input and data analysis.

\subsection{Data analysis}

The data is input into IBM SPSS.23 software. The basic information of the sample uses descriptive statistics and frequency statistics. Univariate analysis used $t$ test and analysis of variance (ANOVA). Use a multiple linear regression model to explore the decisive factors affecting college students' knowledge of COVID-19. In this study, $\mathrm{p}<0.05$ was considered statistically significant. 


\section{RESULTS}

\subsection{Basic Information}

A total of 3059 people participated in this study. Their average age is $20.74 \pm 1.76$ years. Among them, men $(50.57 \%)$ and women $(49.43 \%)$. They live in rural areas $(63.55 \%)$ and cities $(36.45 \%)$. Provinces: Sichuan (33.14\%), Yunnan (33.47\%), Guizhou (33.39\%). Grades: Freshman (37.95\%), sophomore $(15.95 \%)$, junior $(26.48 \%)$, senior $(19.61 \%)$. Science and engineering $(48.9 \%)$ and liberal arts $(51.1 \%)$ (Table 1$)$.

Table 1. Demographic characteristics of participants in a survey about COVID-19,2020 ( $\mathrm{n}=3059)$

\begin{tabular}{|c|c|}
\hline \multicolumn{2}{|l|}{ Characteristics } \\
\hline \multicolumn{2}{|l|}{ Age (year) } \\
\hline Mean \pm SD & $20.74 \pm 1.76$ \\
\hline \multicolumn{2}{|l|}{ Gender n (\%) } \\
\hline Male & $1547(50.57)$ \\
\hline Female & $1512(49.43)$ \\
\hline \multicolumn{2}{|c|}{ Current residencen n (\%) } \\
\hline Urban area & $1115(36.45)$ \\
\hline rural area & 1194(63.55) \\
\hline \multicolumn{2}{|l|}{ Graden n (\%) } \\
\hline Freshmen & $1161(37.95)$ \\
\hline Sophomores & $488(15.95)$ \\
\hline Juniors & $810(26.48)$ \\
\hline Seniors & $600(19.61)$ \\
\hline \multicolumn{2}{|c|}{ Subject category n (\%) } \\
\hline Sciences & $1496(48.9)$ \\
\hline Liberal arts & $1563(51.1)$ \\
\hline \multicolumn{2}{|l|}{ Region n (\%) } \\
\hline Sichuan Province & $708(33.14)$ \\
\hline Yunnan Province & $718(33.47)$ \\
\hline Guizhou Province & 813 (33.39) \\
\hline
\end{tabular}

\subsection{COVID-19 knowledge}

The average score of college students'COVID-19 knowledge score is $11.45 \pm 1.34$ points, of which $56.16 \%$ get good and above. Table 2 shows the responses of college students to each question in the knowledge section of COVID-19. College students' answers to the susceptible population of COVID-19 $(48.15 \%)$, transmission route $(32.0 \%)$ and population transmission source $(34.4 \%)$ have a low accuracy rate, while the accuracy rate of other questions is above $88 \%$. Boys have lower knowledge scores than girls. The knowledge score of urban students is higher than that of rural students. The knowledge scores of seniors are higher than those of the other three grades. The knowledge score of science students is lower than that of liberal arts students (Table 3). 
Table 2. Responses to questions in knowledge about COVID-19 ( $\mathrm{n}=3059), \%$

\begin{tabular}{|c|c|c|}
\hline $\mathrm{NO}$ & Item & correct $\mathrm{n}(\%)$ \\
\hline $\mathrm{K} 1$ & What's right about COVID-19? & $2887(94.34)$ \\
\hline $\mathrm{K} 2$ & What is the viral host of COVID-19? & $3046(99.58)$ \\
\hline K3 & $\begin{array}{l}\text { What is the confirmed route of transmission of } \\
\text { COVID- } 19 \text { ? }\end{array}$ & $2080(68.00)$ \\
\hline K4 & $\begin{array}{l}\text { How long is the incubation period of COVID- } \\
19 ?\end{array}$ & $3017(98.63)$ \\
\hline K5 & $\begin{array}{l}\text { What is the source of transmission of COVID- } \\
19 ?\end{array}$ & $2098(68.58)$ \\
\hline K6 & $\begin{array}{l}\text { What kind of people are easily infected with } \\
\text { COVID-19? }\end{array}$ & $1473(48.15)$ \\
\hline K7 & $\begin{array}{l}\text { The main clinical symptoms of COVID-19 } \\
\text { are? }\end{array}$ & $3029(99.02)$ \\
\hline K8 & $\begin{array}{l}\text { What behaviors may increase the risk of } \\
\text { COVID-19? }\end{array}$ & $2886(94.34)$ \\
\hline K9 & $\begin{array}{l}\text { Does serious illness increase the severity of } \\
\text { COVID-19? }\end{array}$ & $2696(88.13)$ \\
\hline K10 & $\begin{array}{l}\text { Is low immunity easy to increase the risk of } \\
\text { COVID-19? }\end{array}$ & $2927(95.68)$ \\
\hline K11 & $\begin{array}{l}\text { What behaviors can reduce the risk of } \\
\text { COVID-19? }\end{array}$ & $2971(97.12)$ \\
\hline K12 & What's right about washing hands frequently? & $2947(96.34)$ \\
\hline K13 & $\begin{array}{l}\text { What are the following measures to help } \\
\text { prevent COVID-19? }\end{array}$ & $2986(97.60)$ \\
\hline
\end{tabular}

Table 3. Univariable analysis of demographic determinants of knowledge about COVID-19, concluded from the survey, 2020

\begin{tabular}{|c|c|c|c|}
\hline \multirow{2}{*}{ Variable } & \multicolumn{3}{|c|}{ Knowledge } \\
\hline & $\mathrm{M} \pm \mathrm{SD}$ & $t / F$ & $p$ \\
\hline \multicolumn{4}{|l|}{ Gender } \\
\hline Male & $11.35 \pm 1.40$ & 4.26 & $<0.001$ \\
\hline Female & $11.56 \pm 1.27$ & & \\
\hline \multicolumn{4}{|l|}{ Current residencen } \\
\hline Urban area & $11.58 \pm 1.30$ & -3.89 & $<0.001$ \\
\hline rural area & $11.38 \pm 1.36$ & & \\
\hline \multicolumn{4}{|l|}{ Gradend } \\
\hline Freshmen & $11.33 \pm 1.33$ & 13.23 & $<0.001$ \\
\hline Sophomores & $11.29 \pm 1.40$ & & \\
\hline Juniors & $11.61 \pm 1.29$ & & \\
\hline Seniors & $11.63 \pm 1.34$ & & \\
\hline \multicolumn{4}{|l|}{ Subject category } \\
\hline Sciences and engineering & $11.37 \pm 1.39$ & 3.60 & $<0.001$ \\
\hline Liberal arts & $11.54 \pm 1.29$ & & \\
\hline \multicolumn{4}{|l|}{ region } \\
\hline Sichuan Province & $11.48 \pm 1.24$ & 1.73 & 0.183 \\
\hline Yunnan Province & $11.00 \pm 1.48$ & & \\
\hline
\end{tabular}




\subsection{COVID-19 information acquisition methods and information topic}

$56.42 \%$ of students have 3 or less ways to obtain daily information. Table 4 shows how college students choose to obtain COVID-19 information every day. "TV" (86.6\%), "Internet" (79.4\%), "family and friends" $(50.2 \%)$, and "schools and teachers" $(48.2 \%)$ are the top four ways to obtain information. Table 5 shows how college students are concerned about the information content of COVID-19. The topics that college students are most concerned about are "Changes in the number of new patients with COVID-19 (94.4\%)", "Prevention methods for COVID-19 (89.1\%)", "Disease characteristics (75.5\%)" and "Dangerous diseases factors $(75.5 \%) "$. College students pay the least attention to the negative news about COVID-19 (13.3\%). $48.48 \%$ of students pay attention to the following topic at the same time every day: "Number of new COVID-19 patients", "Disease characteristics", "Related risk factors" and "preventive measures." The average score of girls' information topic was significantly higher than that of boys. The average score of urban students' information acquisition methods was significantly higher than that of rural students (Table 6、7).

Table 4. Responses to questions in information acquisition methods about COVID-19 (n=3059),\%

\begin{tabular}{|c|c|c|}
\hline $\mathrm{NO}$ & Item & Yes $n(\%)$ \\
\hline M1 & $\begin{array}{l}\text { Do you get COVID-19information } \\
\text { from the Internet every day? }\end{array}$ & $\begin{array}{c}2429 \\
(79.41)\end{array}$ \\
\hline M2 & $\begin{array}{l}\text { Do you get COVID-19information } \\
\text { from your family, relatives and } \\
\text { friends every day? }\end{array}$ & $\begin{array}{c}1544 \\
(50.47)\end{array}$ \\
\hline M3 & $\begin{array}{l}\text { Do you get COVID-19information } \\
\text { from your university and teachers } \\
\text { every day? }\end{array}$ & $\begin{array}{c}1475 \\
(48.22)\end{array}$ \\
\hline M4 & $\begin{array}{l}\text { Do you get COVID-19information } \\
\text { from your community staff every } \\
\text { day? }\end{array}$ & $\begin{array}{c}853 \\
(27.88)\end{array}$ \\
\hline M5 & $\begin{array}{l}\text { Do you get COVID-19information } \\
\text { from TV every day? }\end{array}$ & $\begin{array}{c}2649 \\
(86.60)\end{array}$ \\
\hline M6 & $\begin{array}{l}\text { Do you get COVID-19information } \\
\text { from newspapers every day? }\end{array}$ & $\begin{array}{c}522 \\
(18.05)\end{array}$ \\
\hline M7 & $\begin{array}{l}\text { Do you get COVID-19information } \\
\text { from other sources (other than the } \\
\text { above) every day? }\end{array}$ & $\begin{array}{c}952 \\
(31.12)\end{array}$ \\
\hline
\end{tabular}

Table 5. Responses to questions in topic about COVID-19 ( $\mathrm{n}=3059), \%$

\begin{tabular}{ccc}
\hline NO & Item & Yes $\mathrm{n}(\%)$ \\
\hline S1 & Do you pay attention to the characteristics of COVID-19 symptoms every day? & 2309 \\
& & $(75.48)$ \\
S2 & Do you pay attention to the pathogenic factors of COVID-19 every day? & 2310 \\
& & Do you focus on COVID-19 prevention every day?
\end{tabular}


Table 6. Univariable analysis of demographic determinants of information acquisition methods about COVID-19, concluded from the survey,2020

\begin{tabular}{|c|c|c|c|}
\hline \multirow{2}{*}{ Variable } & \multicolumn{3}{|c|}{ information acquisition methods } \\
\hline & $\mathrm{M} \pm \mathrm{SD}$ & $t / F$ & $p$ \\
\hline \multicolumn{4}{|l|}{ Gender } \\
\hline Male & $3.39 \pm 1.74$ & 0.97 & 0.329 \\
\hline Female & $3.45 \pm 1.60$ & & \\
\hline \multicolumn{4}{|l|}{ Current residence } \\
\hline Urban area & $3.52 \pm 1.75$ & -2.54 & 0.011 \\
\hline rural area & $3.36 \pm 1.62$ & & \\
\hline \multicolumn{4}{|l|}{ Gradend } \\
\hline Freshmen & $3.42 \pm 1.63$ & 0.85 & 0.462 \\
\hline Sophomores & $3.52 \pm 1.77$ & & \\
\hline Juniors & $3.37 \pm 1.63$ & & \\
\hline Seniors & $3.39 \pm 1.72$ & & \\
\hline \multicolumn{4}{|l|}{ Subject category } \\
\hline Sciences and engineering & $3.45 \pm 1.71$ & -1.17 & 0.239 \\
\hline Liberal arts & $3.38 \pm 1.63$ & & \\
\hline \multicolumn{4}{|l|}{ Region } \\
\hline Sichuan Province & $3.50 \pm 1.71$ & 1.90 & 0.155 \\
\hline Yunnan Province & $3.91 \pm 1.70$ & & \\
\hline Guizhou Province & $3.40 \pm 1.67$ & & \\
\hline
\end{tabular}

Table 7. Univariable analysis of demographic determinants of information topic about COVID-19,concluded from the survey ,2020

\begin{tabular}{lccc}
\hline & Variable & \multicolumn{2}{c}{ information acquisition methods } \\
\cline { 2 - 4 } & $\mathrm{M} \pm \mathrm{SD}$ & $t / F$ & $p$ \\
\hline Gender & & & \\
Male & $3.39 \pm 1.07$ & 4.79 & $<0.001$ \\
Female & $3.56 \pm 0.96$ & & \\
Current residence & & & 0.441 \\
Urban area & $3.46 \pm 1.03$ & 0.77 &
\end{tabular}


rural area

Gradend

Freshmen

Sophomores

Juniors

Seniors

Subject category

Sciences and engineering

Liberal arts

Region

Sichuan Province

Yunnan Province

Guizhou Province
$3.49 \pm 1.01$

$3.45 \pm 0.98$

1.52

0.206

$3.51 \pm 1.04$

$3.45 \pm 1.05$

$3.55 \pm 1.02$

$3.44 \pm 1.04$

1.77

0.076

$3.51 \pm 0.99$

$3.39 \pm 1.10$

1.67

0.193

$3.49 \pm 1.01$

\subsection{Information needs of COVID-19}

hope to learn more about COVID-19. The information needs score of boys is lower than that of girls. The information demand score of urban students is higher than that of rural students (Table 8).

Table 8. Univariable analysis of demographic determinants of information needs about COVID-19, concluded from the survey ,2020

\begin{tabular}{|c|c|c|c|}
\hline \multirow{2}{*}{ Variable } & \multicolumn{3}{|c|}{ information acquisition methods } \\
\hline & $\mathrm{M} \pm \mathrm{SD}$ & $t / F$ & $p$ \\
\hline \multicolumn{4}{|l|}{ Gender } \\
\hline Male & $37.62 \pm 6.48$ & 4.59 & $<0.001$ \\
\hline Female & $38.63 \pm 5.68$ & & \\
\hline \multicolumn{4}{|l|}{ Current residence } \\
\hline Urban area & $38.43 \pm 6.27$ & -2.04 & 0.041 \\
\hline rural area & $37.96 \pm 6.01$ & & \\
\hline \multicolumn{4}{|l|}{ Gradend } \\
\hline Freshmen & $38.24 \pm 5.77$ & 0.30 & 0.820 \\
\hline Sophomores & $37.95 \pm 6.35$ & & \\
\hline Juniors & $38.05 \pm 6.34$ & & \\
\hline Seniors & $38.17 \pm 6.25$ & & \\
\hline \multicolumn{4}{|l|}{ Subject category } \\
\hline Sciences and engineering & $38.26 \pm 6.14$ & -1.16 & 0.245 \\
\hline Liberal arts & $38.00 \pm 6.08$ & & \\
\hline \multicolumn{4}{|l|}{ Region } \\
\hline Sichuan Province & $37.46 \pm 6.76$ & 1.75 & 0.179 \\
\hline
\end{tabular}


Yunnan Province

Guizhou Province
$37.63 \pm 7.41$

$38.21 \pm 6.01$

\subsection{Information acquisition habits of health information}

The average score of information acquisition habits of college students is $43.39 \pm 7.60$ points. Before the outbreak, mobile phones $(34.5 \%)$, the Internet $(32.5 \%)$ and TV/radio $(30.9 \%)$ were the main ways for college students to obtain health information. The average score of boys' information acquisition habits is higher than that of girls. The average score of urban students' information acquisition habits is higher than that of rural students. The average score of information acquisition habits of science and engineering students is higher than that of liberal arts students (Table 9).

Table 9. Univariable analysis of demographic determinants of information acquisition habit about COVID-19, concluded from the survey, 2020

\begin{tabular}{|c|c|c|c|}
\hline \multirow{2}{*}{ Variable } & \multicolumn{3}{|c|}{ information acquisition habit } \\
\hline & $\mathrm{M} \pm \mathrm{SD}$ & $t / F$ & $p$ \\
\hline \multicolumn{4}{|l|}{ Gender } \\
\hline Male & $44.77 \pm 7.97$ & -6.03 & $<0.001$ \\
\hline Female & $43.12 \pm 7.12$ & & \\
\hline \multicolumn{4}{|l|}{ Current residence } \\
\hline Urban area & $44.20 \pm 7.92$ & & \\
\hline rural area & $43.78 \pm 7.40$ & -1.43 & 0.151 \\
\hline \multicolumn{4}{|l|}{ Gradend } \\
\hline Freshmen & $43.90 \pm 7.45$ & 1.78 & 0.148 \\
\hline Sophomores & $44.46 \pm 7.66$ & & \\
\hline Juniors & $43.50 \pm 7.80$ & & \\
\hline Seniors & $44.16 \pm 7.55$ & & \\
\hline \multicolumn{4}{|l|}{ Subject category } \\
\hline Sciences and engineering & $44.54 \pm 7.69$ & -4.30 & $<0.001$ \\
\hline Liberal arts & $43.36 \pm 7.46$ & & \\
\hline \multicolumn{4}{|l|}{ Region } \\
\hline Sichuan Province & $44.38 \pm 8.11$ & 5.13 & 0.008 \\
\hline Yunnan Province & $47.40 \pm 6.81$ & & \\
\hline Guizhou Province & $43.84 \pm 7.54$ & & \\
\hline
\end{tabular}

\subsection{Impact of environmental epidemic risk and the decisive factor of COVID-19 knowledge}


Table 10. Multiple linear regression analysis of demographic determinants and other influencing factors of knowledge about COVID-19, concluded from the survey ,2020

\begin{tabular}{lcccc}
\hline \multicolumn{1}{c}{ Variable } & \multicolumn{4}{c}{ Knowledge } \\
\cline { 2 - 5 } & $\begin{array}{c}\text { Unstandar-- } \\
\text { dized }\end{array}$ & $\begin{array}{c}\text { Standar- } \\
\text { dized }\end{array}$ & $t$ & Sig. \\
\hline Contrast & B & B & 29.465 & $<0.001$ \\
Gender & 11.765 & - & -2.180 & 0.029 \\
Age & -0.110 & -0.041 & -3.331 & 0.001 \\
Grade & -0.072 & -0.093 & 6.156 & $<0.001$ \\
Regional risk level & 0195 & 0.169 & -1.172 & 0.241 \\
Subject category & -0.089 & -0.021 & -3.355 & $<0.001$ \\
Current residence & -0.166 & -0.062 & 2.902 & 0.004 \\
Information needs & 0.148 & 0.053 & 4.517 & $<0.001$ \\
Information & 0.019 & 0.087 & 2.415 & 0.016 \\
acquisition methods & 0.038 & 0.047 & -0.801 & 0.423 \\
Information & & -0.016 & 2.953 & 0.003 \\
acquisition habit & -0.003 & 0.057 & & \\
Information topic & 0.075 & & & \\
\hline
\end{tabular}

Table $6,7,8,9$ show the survey of COVID-19 knowledge and related information among college students in three areas with different epidemic risks. This study only observed differences in the scores of college students' health information acquisition habits in the three regions. College students currently living in Yunnan Province scored the highest in their health information acquisition habits. Before the outbreak, college students currently living in Yunnan Province obtained more health information from " family members", " professional books, "community propaganda" and "newspapers or magazines" .Table 10 shows that gender, grade, major, current residence, information needs, information acquisition methods and information topic affect college students' COVID-19 knowledge level.

\section{DISCUSSION}

Analysis of the answers to the COVID-19 knowledge questions of college students found that $56.16 \%$ of college students' COVID-19 knowledge scores are above good. This ratio is higher than our survey results on January 30 . At that time, our investigation found that the general public's COVID-19 knowledge rate was $5.4 \%{ }^{[5]}$. This result proves that the public health strategy and health communication strategy adopted by the government in the early stage have a certain effect on raising the awareness of COVID-19 among college students. College students have a good understanding of virus names, virus hosts, incubation period, clinical symptoms, hand-washing methods, and disease risk-increasing factors (the correct rate is above $88 \%$ ). However, their answer to the three knowledge points of susceptible population, transmission route and population transmission source is relatively low. The reason for this phenomenon may be: with the development of the epidemic, the clinical characteristics of the disease are constantly being summarized, and the disease treatment guidelines are constantly being updated, but some college students may not have acquired this new knowledge. Therefore, how to help college students update their knowledge of the disease in a timely manner is also a top priority for the prevention and control of COVID-19.

This study analyzed the information-related behavior of college students and found that during the pandemic, television and the Internet are the main ways for college students to obtain COVID-19-related information. During the COVID-19 epidemic, the main way for college students to obtain COVID-19 information is the same as their main way to obtain health information before the epidemic. However, before COVID-19, the Internet ranked first. After COVID-19, TV ranked first. Analyzing the reason, it may be related to the national media, which broadcasts the COVID-19 information more credible. Therefore, it is very important to increase the spread of COVID-19 information in national and local television media, popular portals and social media. 
Especially through these channels to report clinical discovery of new disease information.

From the daily information acquisition channels of college students, it can be seen that during the COVID19 epidemic, "family and friends (50.2\%)", "schools and teachers $(48.2 \%)$ " have also become important sources for college students to obtain COVID-19 information. What deserves attention is the way to get information about "schools and teachers". During the investigation, all Chinese universities were closed, and students were studying online at home. Schools and teachers have the opportunity to keep in touch with students regularly through the Internet. Therefore, the government can cooperate with the education department to strengthen the construction of school health information dissemination channels, and timely disseminate COVID-19-related information to students, especially clinically updated disease information. In addition, digital health literacy education interventions can also be conducted through schools to enhance students' understanding, acquisition and decision-making capabilities of COVID-19 information.

Studies have found that public awareness of infectious diseases will affect the occurrence and prevalence of infectious diseases. People who know more about infectious diseases are more willing to learn about hygiene and are more willing to maintain good personal hygiene habits. If people know little about the prevention and treatment of infectious diseases, their ability to maintain health may be insufficient. This study found that gender, grade, major, current residence, information needs, information acquisition methods, and information topics all affect college students' understanding of COVID-19. Therefore, combined with the research results, we suggest that it is necessary to strengthen the use of different publicity methods and channels to disseminate knowledge of COVID-19, the latest disease characteristics, related risk factors and prevention measures. Especially when a new version of disease-related information appears, it is necessary to emphasize with the public the differences between the new version and the old version.

The study found that, despite the different levels of epidemic risk, college students have different information acquisition habits. However, during the COVID-19 period, the regional epidemic risk level will not have a significant impact on the information behavior and COVID-19 knowledge of college students. In addition, we suggest that in the COVID-19 health education of college students, the health belief education of college students should be strengthened to promote them to transform knowledge into action.

Limited by the sample size and sampling method of this questionnaire, when the sample size increases, the results of this survey may change. However, through this survey, we can understand the COVID-19 knowledge level, information acquisition methods, information topics, information needs and characteristics of information acquisition habits of college students, aiming to provide reference for the prevention work of relevant departments, control and intervention decision-making. At present, the global public is still facing a serious health threat from COVID-19. This is not only a global war against COVID-19, but also a health education course for ordinary people. COVID-19 may even have an impact on the life philosophy and lifestyle of the public. Therefore, the experience of different national public health strategies and health communication strategies will help the global COVID-19 governance. We suggest that in response to the behaviors and needs of different groups of people, we should more accurately use multiple channels and adopt multiple propaganda methods to promptly and effectively disseminate disease-related information to the society to guide the public to respond.

\section{CONCLUSION}

We suggest that in response to the behaviors and needs of different groups of people, we should more accurately use multiple channels and adopt multiple propaganda methods to promptly and effectively disseminate disease-related information to the society to guide the public to respond.

\section{AUTHORS' CONTRIBUTIONS}

LL conceived the study,designed the research tools, contributed to the data collection, carried out data analyses and interpretation. LL and SNQ drafted the manuscript. All authors have read and approved the final manuscript.

\section{ACKNOWLEDGMENTS}

Thanks for the support from the Doctor's Fund of Guizhou Normal University ( No.GZNUD[2018]-8).

\section{REFERENCES}

[1]WHO.Healthtopics,coronavirus.https://www.who.int/ health topics/coronavirus.Accessed24Mar2020

[2]Almutairi KM,AlHelih EM,Moussa M,et al.Awareness,attitudes, and practices related to coronavirusp and emicamong public in Saudi Arabia .Family Community Health ,2015 ,38:332340.

[3]Choi JS ,Kim KM.Infection control knowledge,attitude,practice, and risk perception of occupational exposure to Zikavirus among nursing students in Korea:across-sectional survey.J Infect Public Health ,2018,11:840-844. 
[4]Madhav N,Oppenheim B,Gallivan $\mathrm{M}$ et al.Pandemics:risks,impacts, and mitigation,chap17.
In:Jamis
on
DT,Gelb
and

H,HortonSetal(eds)Disease control priorities:improving health and reducing poverty,3rdedn.The International Bank for Reconstruction and Development/TheWorldBank, Washington(DC).20 17

[5]Luo L,Zeng XJ,Liao $X$ et al.Disease cognition, coping style and exercise behavior among the public during novel coronavirus epidemic: an online survey.Chinese Journal of Public Health,2020,36(2):156-159 